\title{
Parapheromones Suppress Chemotherapy Side Effects
}

\author{
Goeun Lee, Eunhee Yang, Sojin Kim, Cheung-Seog Park, Yong Seek Park, \\ and Young-Ho Jin \\ Departments of Physiology (G.L., E.Y., S.K., Y.-H.J.) and Micro Biology (C.-S.P., Y.S.P.), College of Medicine, Kyung Hee \\ University, Seoul, Republic of Korea
}

Received June 12, 2018; accepted August 17, 2018

\section{ABSTRACT}

The cytotoxic drugs used in chemotherapy are often accompanied by nausea and vomiting. Despite the use of antiemetic drugs, chemotherapy-induced nausea and vomiting (CINV) remain significant side effects for cancer patients and are associated with serotonin type 3 receptor $\left(5-\mathrm{HT}_{3} \mathrm{R}\right)$ activation in the brainstem. Farnesol and nerolidol are sesquiterpene alcohols found in essential oils of plants such as roses, citronella, and lemon grass and are used as antiemetic parapheromones. Medicinal plants often are effective in treating gastrointestinal disorders, including CINV, although the mechanism of action remains unclear. In the current work, the antiemetic efficacy of the naturally occurring racemic mixture of farnesol ( $m$-farnesol) and nerolidol ( $m$-nerolidol) against cisplatin CINV was tested using the pica behavior (consumption of nonnutritive substances) of rats. Animals treated with $m$-farnesol or $m$-nerolidol consumed a smaller amount of kaolin than of saline-treated control animals. This result is consistent with the antiemetic efficacy of farnesol and nerolidol. Compared with controls, $m$-farnesol- but not $m$-nerolidol-treated animals consumed more food and lost less body weight. Thus, farnesol effectively reduced appetite suppression and weight loss induced by cisplatin. In separate experiments, isomers of farnesol and nerolidol were tested on 5-HT-induced responses of acutely isolated nodose neurons using patch-clamp methods. All the tested constituents inhibited $5-\mathrm{HT}_{3} \mathrm{R}$-mediated current in a noncompetitive manner. Thus, both farnesol and nerolidol may exert antiemetic efficacy by inhibiting 5-HT signaling in cranial visceral afferents, resulting in interruption of emetogenic signaling; however, nerolidol failed to suppress cisplatin-induced anorexia and weight loss, suggesting that additional mechanisms may contribute.

\section{Introduction}

The cytotoxic drugs used in chemotherapy cause diverse adverse effects that include nausea and vomiting (NV), diarrhea, anorexia, and weight loss (Hofman et al., 2004; Devlin et al., 2017). These chemotherapy-induced side effects often interrupt drug treatment and negatively impact outcome of the therapy (Andreyev et al., 1998; Hess et al., 2007). NV, the most common and debilitating of side effects, is commonly treated with antiemetic drugs, including serotonin type 3 receptor $\left(5-\mathrm{HT}_{3} \mathrm{R}\right)$ antagonists, corticosteroids, and substance $\mathrm{P}$ antagonists. Activation $5-\mathrm{HT}_{3} \mathrm{R}$ in the brainstem is associated with triggering nausea pathways, and vagal afferents appear critical in these responses (Babic and Browning, 2014). Nevertheless, many cancer patients still suffer chemotherapyinduced nausea and vomiting (CINV) (Haiderali et al., 2011; Hernandez Torres et al., 2015). To suppress CINV further, medicinal plants (i. e., ginger and bitter orange) are often recommended (Pillai et al., 2011; Suryawanshi, 2011; Ryan et al., 2012). Sesquiterpene alcohols farnesol and nerolidol

This work was supported by the National Research Foundation of Korea [NRF-2017R1D1A1B03033436].

https://doi.org/10.1124/jpet.118.251363.
(Fig. 1) are common constituents of those medicinal plants and widely exist in fruits and herbs.

These compounds are used widely in perfumes as well as in food additives to enhance flavors (Suryawanshi, 2011; Nampoothiri et al., 2012; Chan et al., 2016). These constituents have antimicrobial and antineoplastic activity; however, their actions in CINV are not understood (Jabra-Rizk et al., 2006; Joo and Jetten, 2010). Plant-derived monoterpenoids with $5-\mathrm{HT}_{3} \mathrm{R}$-inhibiting potency have potential antiemetic efficacy to inhibit diverse gastrointestinal symptoms, including NV (Tyers and Freeman, 1992; Ashoor et al., 2013; Jarvis et al., 2016). Such evidence suggests that farnesol and nerolidol may have potential antiemetic efficacy against CINV.

To evaluate this assumption, we tested the functional efficacy of farnesol and nerolidol on CINV in a rat-pica model. We also assessed their potential mechanism of action by assaying effects on $5-\mathrm{HT}_{3} \mathrm{R}$-mediated currents in acutely isolated visceral afferent nodose neurons.

\section{Materials and Methods}

Ethics Statement. All animal procedures were conducted with the approval of the institutional Animal Care and Use Committee of

ABBREVIATIONS: 5- $\mathrm{HT}_{3} \mathrm{R}$, serotonin type 3 receptor; ACSF, artificial cerebrospinal fluid; CINV, chemotherapy-induced nausea and vomiting; MA, megestrol acetate; $m$-farnesol, racemic mixture of farnesol; $m$-nerolidol, racemic mixture of nerolidol; NV, nausea and vomiting; RM ANOVA, repeat measures analysis of variance. 


\section{Linalool}<smiles>C=CC(C)(O)CCC=C(C)C</smiles>

\section{Farnesol}

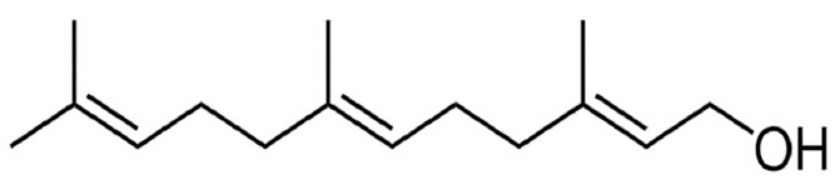

Nerolidol

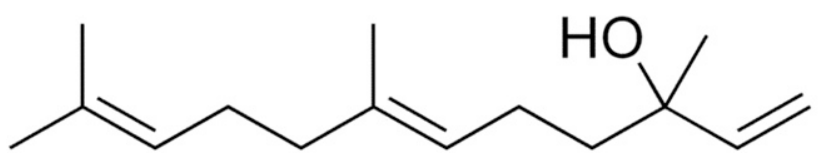

Fig. 1. Chemical structures of nerolidol, farnesol, and linalool.

Kyung Hee University (KHUASP(SE)-17-123). These procedures were in accordance with the National Veterinary Research \& Quarantine Service guidelines of the Republic of Korea.

Kaolin Preparation. Kaolin (hydrated aluminum silicate; SigmaAldrich, St. Louis, MO) was mixed with $1 \%$ gum Arabic (Sigma-Aldrich), molded to rods the same size as that of the food pellets, and then dried at room temperature. Kaolin and food were provided in separate compartments in a divided food hopper.

Experimental Protocol and Drug Administration for Pica Test. Seven-week-old male Wistar rats (Orient Bio Inc., Seongnam, Korea) were housed in plastic cages $(26 \times 42 \times 18 \mathrm{~cm})$ and allowed free access to food, kaolin, and water. The cages were in a temperaturecontrolled room with 12 hours of light from 09:00 and 12 hours of darkness from 21:00. All animals were sacrificed at the end of the study by exposure to a rising concentration of $\mathrm{CO}_{2}$. The rats were adapted for 3 days before the start of the experiment. The animals received cisplatin $(6 \mathrm{mg} / \mathrm{kg})$ or saline intraperitoneally for 4 consecutive days. The dose of cisplatin was chosen based on previous studies of kaolin intake in the rat (Takeda et al., 1993; De Jonghe et al., 2009). The volume of cisplatin solution administered was adjusted with saline to $100 \mathrm{ml} / \mathrm{kg}$ body weight. Farnesol (100 or $500 \mathrm{mg} / \mathrm{kg}$ ), nerolidol (100 or $500 \mathrm{mg} / \mathrm{kg}$ ), and ondansetron $(3 \mathrm{mg} / \mathrm{kg}$ ) were administrated orally 60 minutes before the administration of cisplatin. All experimental parameters (body weight, food and water intake, kaolin consumption) were measured daily between hours 10:00 and 11:00 throughout the study.

Acute Dissociation of Nodose Neuron. Visceral afferent neuron cell bodies, including those innervating the gastrointestinal system, are contained in the nodose ganglion. Nodose neurons were dissociated using procedures previously described elsewhere (Kim et al., 2015). Briefly, in deeply anesthetized (Zoletil, Virbac, France) 3- to 4-week-old male Wistar rats, the vagus nerve and the attached ganglion were separated from surrounding tissue and immediately placed into a Petri dish containing $4^{\circ} \mathrm{C}$ artificial cerebrospinal fluid (ACSF), which was composed of the following (in $\mathrm{mM}$ ): $125 \mathrm{NaCl}, 3 \mathrm{KCl}, 1.2 \mathrm{KH}_{2} \mathrm{PO}_{4}, 1.2$ $\mathrm{MgSO}_{4}, 25 \mathrm{NaHCO}_{3}, 10$ glucose, and $2 \mathrm{CaCl}_{2}$, and bubbled with $95 \%$ $\mathrm{O}_{2}-5 \% \mathrm{CO}_{2}$. After removing excess connective tissues. Then the nodose ganglion was incubated for $30-45$ minutes at $31^{\circ} \mathrm{C}$ in an ACSF solution containing protease (type $2 \mathrm{~S}$ trypsin, 5 to $6 \mathrm{mg} / \mathrm{ml}$ at $1310 \mathrm{U} / \mathrm{mg}$; SigmaAldrich). After protease treatment, the ganglion was placed in enzymefree ACSF for 2-4 hours at room temperature. The ganglia were mechanically dispersed using fire-polished Pasteur pipettes in a glassbottom perfusion chamber filled with artificial external recording solution containing (in $\mathrm{mM}$ ): $150 \mathrm{NaCl}, 5 \mathrm{KCl}, 1 \mathrm{MgCl}_{2}, 2 \mathrm{CaCl}_{2}$, 10 HEPES; 10 glucose (pH was adjusted to 7.4 with Tris base).

Electrical Measurements and Data Analysis. For voltageclamp recording, isolated neurons were visualized using a phasecontrast microscope (Eclipse Ti; Nikon, Tokyo, Japan). Recordings used a Multiclamp 700B (Molecular Devices, Sunnyvale, CA) and pClamp 9 software (Molecular Devices). To minimize changes in intracellular constituents, we used a perforated-patch method (Akaike and Harata, 1994). Recording electrodes were back-filled with a nystatin-containing pipette solution composed of the following (in $\mathrm{mM}$ ): $50 \mathrm{KCl}, 100 \mathrm{~K}$ gluconate, and 10 HEPES; the $\mathrm{pH}$ of this solution was adjusted to 7.2 with Tris-OH. Final concentration of nystatin was $450 \mu \mathrm{g} / \mathrm{ml}$. The nystatin-internal solution-filled patch pipettes had 5 to $6 \mathrm{M} \Omega$ resistance. Under our recording conditions, acutely dispersed nodose neurons have a resting membrane potential $-52 \pm 4 \mathrm{mV}(n=6)$. Currents were sampled at $10 \mathrm{kHz}$ with $3-\mathrm{kHz}$ filtering. All experiments were conducted at room temperature $\left(21-22^{\circ} \mathrm{C}\right)$. Data were analyzed offline using pClamp 9 software. Concentration-response relations were fit according to a modified Michaelis-Menten equation (eq. 2) using a leastsquare fitting routine 1 :

$$
\mathrm{I}=\mathrm{I}_{\max }\left[\mathrm{C}^{\mathrm{n}} /\left(\mathrm{C}^{\mathrm{n}}+\mathrm{EC}_{50}{ }^{\mathrm{n}}\right)\right],
$$

where $I$ is the drug-induced current amplitude, $I_{\max }$ is the maximum current amplitude, and $\mathrm{C}$ is the corresponding drug concentration. $\mathrm{EC}_{50}$ and $n$ denote the half-maximum effective concentration and the Hill coefficient, respectively. The data for the concentration-inhibition curve were analyzed using the following equation (eq. 2) by a leastsquare method:

$$
\mathrm{I}=1-\left[\mathrm{C}^{\mathrm{n}} /\left(\mathrm{C}^{\mathrm{n}}+\mathrm{IC}_{50}{ }^{\mathrm{n}}\right)\right]
$$

where $\mathrm{I}$ is the current amplitude without antagonists, $\mathrm{C}$ is the concentration of the antagonist, and $\mathrm{IC}_{50}$ is the concentration at the half-maximum inhibition.

Drugs. Serotonin (5-HT), trans, trans-farnesol, racemic mixture of farnesol (m-farnesol), trans-nerolidol, cis-nerolidol, racemic mixture of cis and trans nerolidol (m-nerolidol), and linalool were purchased from Sigma-Aldrich. The $5-\mathrm{HT}_{3} \mathrm{R}$ selective antagonist ondansetron was purchased from Tocris Cookson (Ballwin, MO). Farnesol and nerolidol were first dissolved in ethanol, and then the stock solution was diluted with the external solution just before use. The final concentrations of ethanol were always $<0.01 \%$. At these concentrations, ethanol alone had no effect on membrane potential or on electrical activity. All drugs were applied via a rapid application Y-tube microperfusion system that provided complete changes in the solution surrounding the recorded neurons within 0.1 second (Murase et al., 1989).

Statistical Analysis. Values were expressed as the mean \pm S.E.M. Statistical comparisons between two groups were analyzed by the Student's $t$ test. For multiple comparisons, one-way or two-way analysis of variance (ANOVA) was followed by post hoc testing for multiple comparisons (Bonferroni/Dunn's correction, StatView; SAS Institute Inc., Cary, NC). Differences were considered statistically significant for $P$ values $<0.05$.

\section{Results}

Nerolidol and Farnesol Reduce Cisplatin-Induced Kaolin Consumption. Antiemetic effects of farnesol and nerolidol were tested on cisplatin-induced emesis in a rat-pica model with their naturally occurring racemic mixtures $m$-farnesol and $m$-nerolidol. Animals were conditioned for 3 days before the 


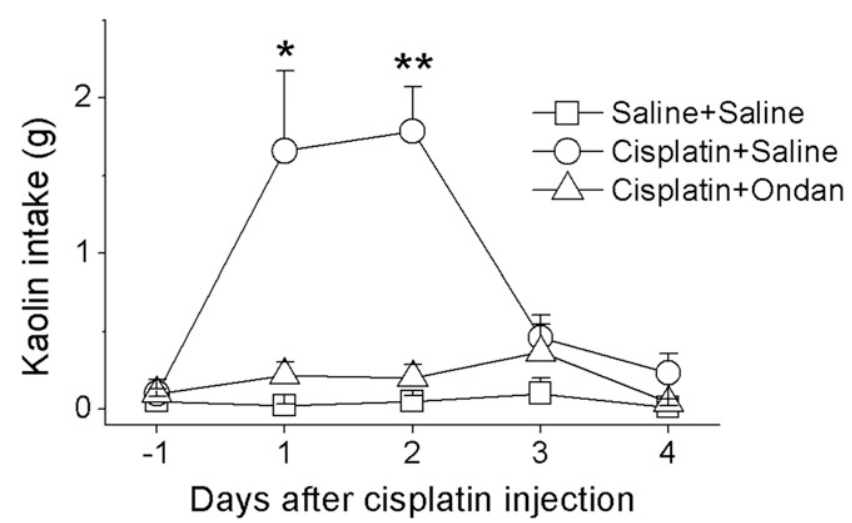

Fig. 2. Effects of ondansetron (Ondan) on cisplatin-induced increase in kaolin intake. Cisplatin or vehicle (saline) was administered on day 1. Ondansetron was administered 60 minutes before cisplatin. Data are expressed as mean \pm S.E.M. $n=6$. ${ }^{*} P<0.05 ; * * P<0.01$ vs. saline-treated group.

experiments by intraperitoneal cisplatin injections $(6 \mathrm{mg} / \mathrm{kg}$ per day). In a control experiment, cisplatin administration significantly increased kaolin consumption $[P<0.01$, repeat measures analysis of variance (RM ANOVA) compared with days before injection (Fig. 2). On days 1 and 2 of cisplatin administration, kaolin intake was significantly greater than the in salinetreated group ( $n=6, P<0.01$, RM ANOVA). Treatment with the 5 - $\mathrm{HT}_{3} \mathrm{R}$ antagonist, ondansetron $(3 \mathrm{mg} / \mathrm{kg}$, p.o.) prevented cisplatin-mediated increases in kaolin intake. Kaolin intake was not significantly different in the saline-saline and cisplatin-ondansetron group animals. In the same conditions, $m$-nerolidol and $m$-farnesol (100 mg/kg) significantly inhibited the cisplatin-induced increase in kaolin intake at days 2 compared with the cisplatin-saline group ( $m$-nerolidol $P<0.05, m$-farnesol $P<0.01$; Fig. 3 ). When their concentrations were increased to $500 \mathrm{mg} / \mathrm{kg}$, both compounds reduced the cisplatin-induced kaolin intake at days 1 and $2(P<0.01)$. Neither $m$-farnesol nor $m$-nerolidol alone had a significant effect on the kaolin intake (Fig. 3B).
Farnesol and Nerolidol Effects on Cisplatin-Induced Changes in Body Weight, Food and Water Intake. In addition to NV, cytotoxic chemotherapy also suppress appetite for food and reduces body weight (for review, see Suzuki et al., 2013). In our experiments, cisplatin reduced body weight and food and water intake (Fig. 4). Unexpectedly, animals treated with $m$-farnesol were less affected by cisplatin-induced side effects. Cisplatin caused weight loss in all tested groups but was significantly reduced by $100 \mathrm{mg} / \mathrm{kg}(P<0.05, \mathrm{RM}$ AVOVA) and $500 \mathrm{mg} / \mathrm{kg}(P<0.01, \mathrm{RM}$ AVOVA $) m$-farnesol treatment (Fig. 4A). After 4 days of cisplatin administration, rats treated with $m$-farnesol, 100 and $500 \mathrm{mg} / \mathrm{kg}$, retained $86 \% \pm 2.4 \%$ and $92 \% \pm 4.8 \%$ of their original body weight, respectively, and that was significantly higher than the control group weight $(83 \% \pm 2.2 \%, P<0.05)$. In contrast, neither $m$-nerolidol nor ondansetron affected cisplatin-induced weight loss. Cisplatin-treated animals consumed progressively smaller amounts of food, whereas animals treated with $m$-farnesol (500 $\mathrm{mg} / \mathrm{kg}$ ) consumed significantly more food than did the control groups on days 1 and 4 ( $P<0.05$, RM AVOVA) (Fig. 4B). Moreover, $m$-farnesol (100 and $500 \mathrm{mg} / \mathrm{kg}$ ) and ondansetron significantly inhibited the cisplatin-induced decreases in water intake at day $4(P<0.05$ or 0.01$)$. Meanwhile, $m$-nerolidol had no effect on cisplatin-induced decrease in food and water intake (Fig. 4C). $M$-farnesol (500 mg) alone did not affect body weight or food and water intake compared with saline-treated controls $(P>0.05)$.

Farnesol and Nerolidol Inhibit 5-HT Currents in Sensory Neurons. Our work has revealed a novel antiemetic efficacy of farnesol and nerolidol against CINV. The mechanisms or sites of action for these antiemetic compounds are not known. Recent studies of the natural monoterpenoids (i.e., menthol, citral, and linalool) indicate efficacy in $5-\mathrm{HT}_{3} \mathrm{R}$ inhibition (Ashoor et al., 2013; Jarvis et al., 2016). These results, coupled with the finding that $5-\mathrm{HT}_{3} \mathrm{R}$ selective antagonists suppress CINV (Tyers and Freeman, 1992), suggest that this receptor may be targeted. As $5-\mathrm{HT}_{3} \mathrm{Rs}$ are prominently

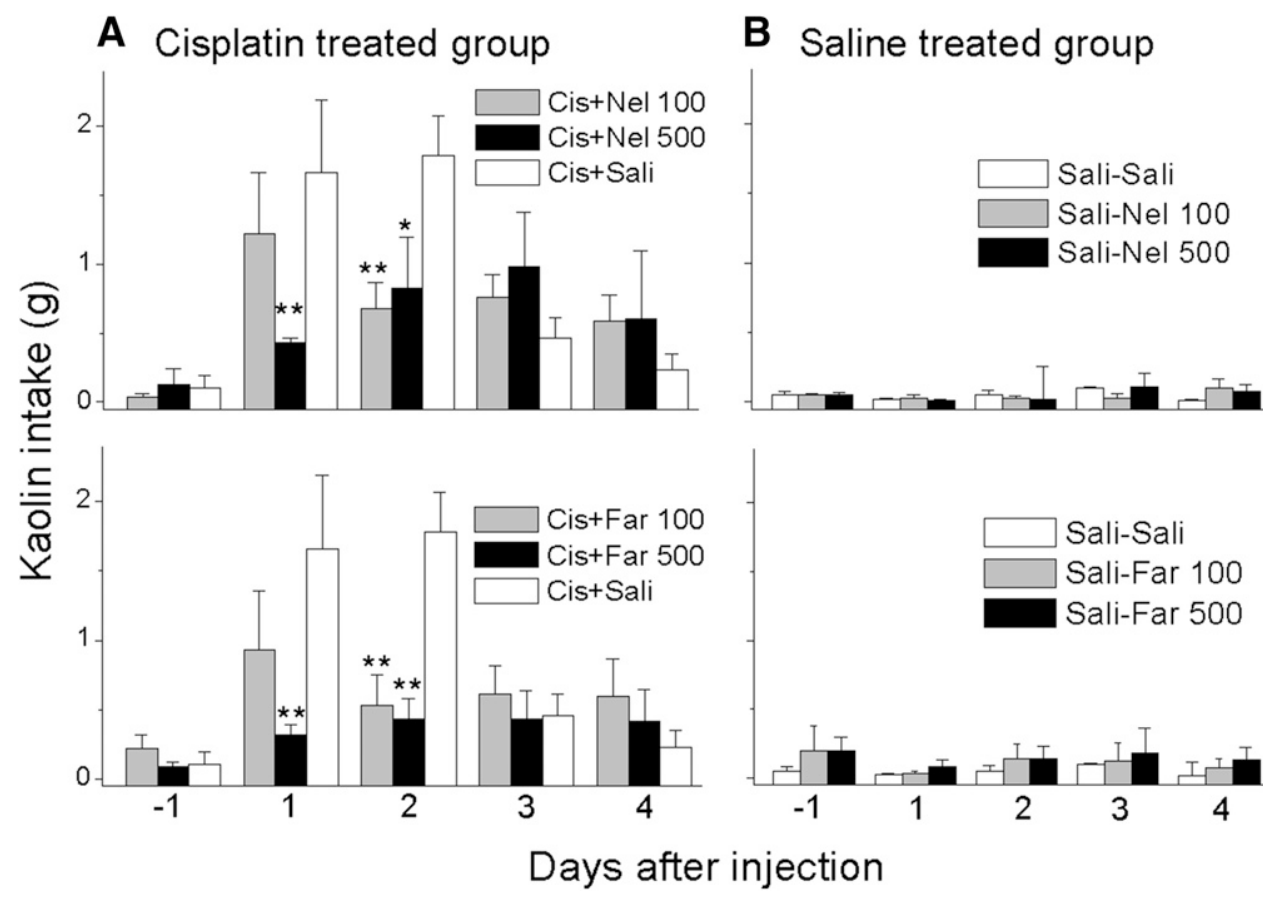

Fig. 3. Effects of $m$-nerolidol (Nel) and $m$-farnesol (Far) on cisplatin-induced kaolin intake. (A) Nerolidol (100 and $500 \mathrm{mg} / \mathrm{kg}$, p.o.) and farnesol (100 and $500 \mathrm{mg} / \mathrm{kg}$, p.o.) were administered 60 minutes before cisplatin. ${ }^{*} P<0.05$; $* * P<0.01$ vs. cisplatin-saline-treated group. (B) Nerolidol and farnesol were administered 60 minutes before saline. All data are expressed as mean \pm S.E.M. 

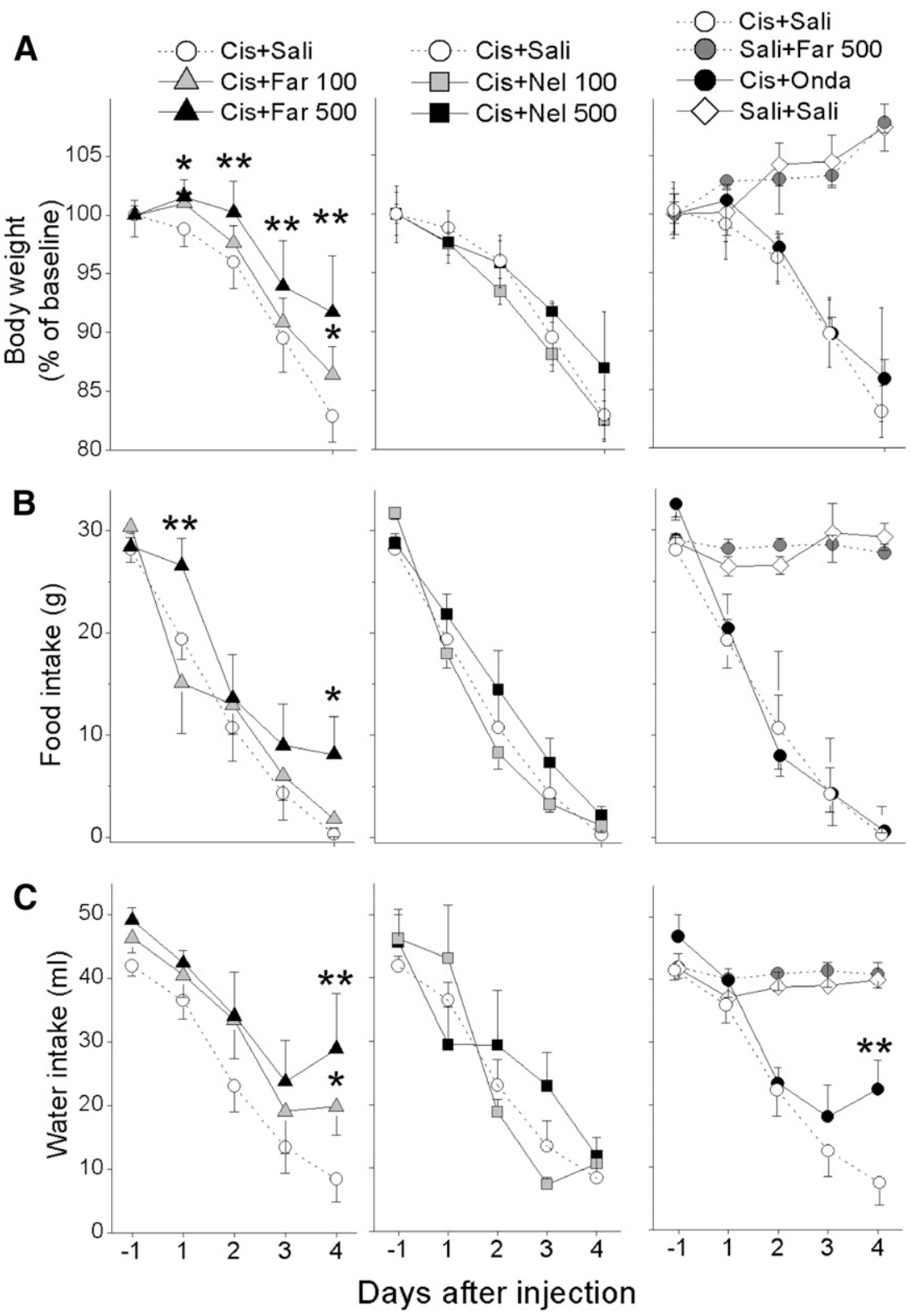

Fig. 4. Effects of farnesol (Far), nerolidol (Nel), and ondansetron (Onda) on cisplatin (Cis)-induced body weight (A), food intake (B), and water intake (C) in rats. Farnesol (100 and $500 \mathrm{mg} / \mathrm{kg}$, p.o.), nerolidol (100 and $500 \mathrm{mg} / \mathrm{kg}$, p.o.), and ondansetron ( $3 \mathrm{mg} / \mathrm{kg}$, p.o.) were administered 60 minutes before cisplatin $(6 \mathrm{mg} / \mathrm{kg}$, i.p. $)$ injection. Data are expressed as mean \pm S.E.M. $n=6$ to 7. ${ }^{*} P<0.05 ; * * P<0.01$ compared with cisplatin-saline. expressed in vagal afferents, which participate in emetic pathways (Babic and Browning, 2014), we decided to test farnesol and nerolidol on visceral afferent nodose neurons.

5 -HT induced inward currents in $38 \%$ ( $n=70 / 184$ neurons) of the tested neurons, as previously reported (Kim et al., 2015). This response was completely inhibited by the $5-\mathrm{HT}_{3} \mathrm{R}$ selective antagonist ondansetron $(n=8)$. The 5 -HT-evoked inward currents increased in a concentration-dependent manner (Fig. 5). The 5-HT current amplitude was well fit by the Michaelis-Menten equation, in which the $\mathrm{EC}_{50}$ and the Hill coefficient were 9.1 and 1 , respectively. Thus, fast application of $\geq 1 \mu \mathrm{M}$ 5-HT evoked inward current responses in nodose neurons by activating $5-\mathrm{HT}_{3} \mathrm{Rs}$.

We tested the effect of farnesol and nerolidol on the $5-\mathrm{HT}_{3} \mathrm{R}$ currents, including their stereoisomers and racemic mixtures independently. In addition, we compared linalool, a monoterpene alcohol, to compare with farnesol and three forms of nerolidol (cis- and trans-isomers and their racemic mixture) (Fig. 6A). The order of inhibitory potency was cis-nerolidol $>m$-nerolidol $>$ trans-nerolidol. The $\mathrm{IC}_{50}$ of $m$-nerolidol was 2 -fold lower than trans-nerolidol and 1.3 times higher than cis-nerolidol (Table 1). Farnesol has four different isomers; among them, trans, trans from isomer is the most common in nature. Trans, trans-farnesol, and a racemic mixture of farnesol ( $m$-farnesol) inhibited the 5-HT response in a concentration-dependent manner (Fig. 6B) with an estimated $\mathrm{IC}_{50} \mathrm{~s}$ of 2.7 and $3.9 \mu \mathrm{M}$ for trans, trans-farnesol, and $m$-farnesol, respectively (Table 1); however, linalool failed to inhibit 5-HT response, even at $100 \mu \mathrm{M}$. In summary, cis-nerolidol and trans, trans-farnesol have the highest inhibitory efficacies against 5-HT currents in nodose neurons, respectively.

Farnesol and Nerolidol Act as Noncompetitive Antagonists. To characterize the inhibitory mechanism of farnesol and nerolidol on the $5-\mathrm{HT}_{3} \mathrm{Rs}, 5-\mathrm{HT}$ concentrationresponse curves were examined in the presence of cis-nerolidol or trans, trans-farnesol. The maximum responses to $1 \mathrm{mM} 5-\mathrm{HT}$ were significantly decreased by cis-nerolidol $(P<0.05, n=5)$ to $82 \% \pm 5.9 \%, 45 \% \pm 3.5 \%$, and $19 \% \pm 2.0 \%$ of control values for 

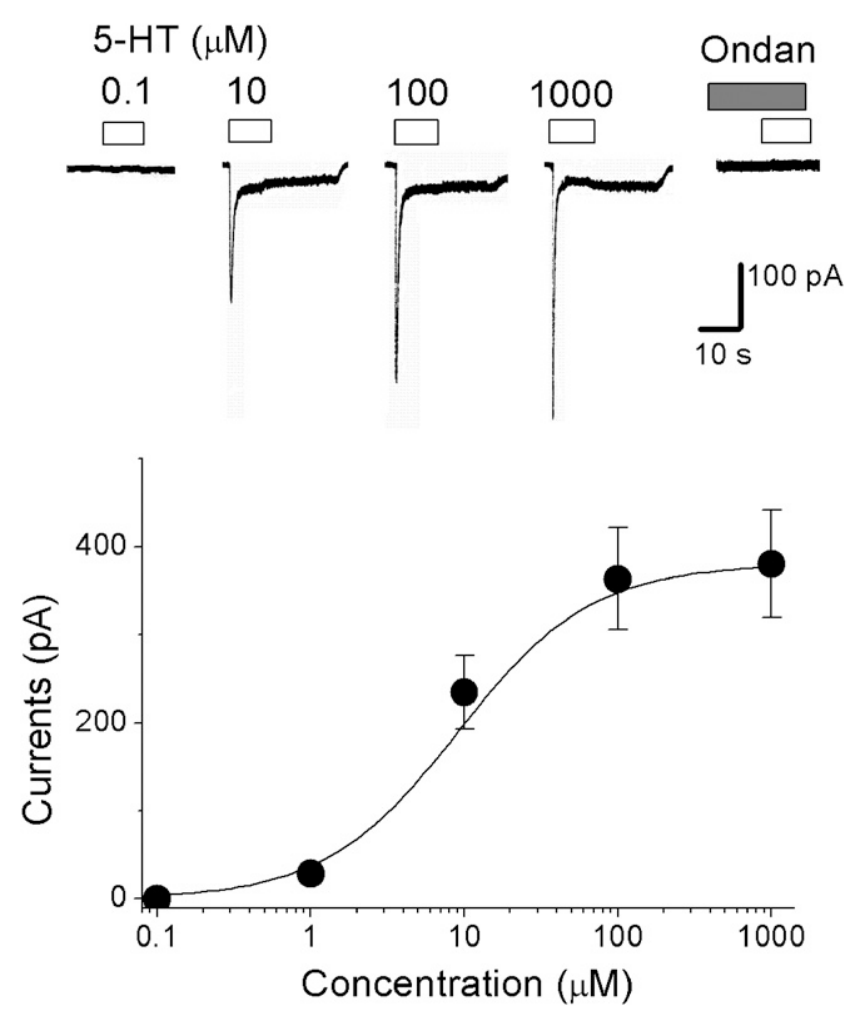

Fig. 5. 5-HT-induced inward current in acutely dispersed afferent vagus neurons. The traces show that 5 -HT evoked currents at selected concentrations. In the same neurons, $100 \mathrm{nM}$ ondansetron (Ondan) blocked $1 \mathrm{mM}$ 5-HT-induced currents. The graphs show concentrationresponse relationships for 5-HT. Points and vertical lines represent the mean and S.E.M. from eight different neurons. All current recordings were made at a holding potential of $-50 \mathrm{mV}$.

2, 5, and $10 \mu \mathrm{M}$, respectively (Fig. 7); however, the $\mathrm{EC}_{50}$ value for 5-HT was not affected by cis-nerolidol $(P>0.05)$. Analysis with Lineweaver-Burk double reciprocal plot indicates that cis-nerolidol inhibits the 5-HT response noncompetitively. Similarly, trans, trans-farnesol significantly decreased $1 \mathrm{mM}$ 5 -HT responses $(P<0.05, n=5)$ to $98 \% \pm 0.1 \%, 67 \% \pm 11.2 \%$, and $48 \% \pm 12.4 \%$ of control values, for 1,3 , and $5 \mu \mathrm{M}$, respectively, without altering the $5-\mathrm{HT} \mathrm{EC}_{50}(P>0.05)$.
Lineweaver-Burk analysis shows that trans, trans-farnesol also inhibits the 5-HT response noncompetitively.

\section{Discussion}

Our experiments indicate that naturally occurring racemic mixtures of $m$-farnesol and $m$-nerolidol acting at $5-\mathrm{HT}_{3} \mathrm{Rs}$ exert antiemetic efficacy in a cisplatin-induced pica behavior assay. $M$-farnesol also reduced the cisplatin-induced decreased weight and food and water intake. A selective $5-\mathrm{HT}_{3} \mathrm{R}$ antagonist, ondansetron, and $m$-nerolidol had no effect on the cisplatin-induced decrease in weight and food and water intake. Our electrophysiologic recordings indicate that sesquiterpene alcohol isomers of farnesol and nerolidol inhibited 5-HT-evoked responses in a concentration-dependent manner at vagal afferent neurons, a potential site of action in the behavioral assays. The order of inhibitory potency was trans, trans-farnesol $>$ racemic mixture-farnesol $(m$-farnesol $)>$ cis-nerolidol $>$ racemic mixturenerolidol $(m$-nerolidol $)>$ trans-nerolidol. The highest potency inhibitors, trans, trans-farnesol, and cis-nerolidol, noncompetitively inhibited 5-HT nodose responses.

Antiemetic Action of Farnesol and Nerolidol against Cytotoxic CINV. Pica behavior in rats closely parallels the pharmacologic mechanisms of vomiting in humans (Takeda et al., 1993). Here, we found that naturally occurring racemic mixtures of farnesol suppressed cisplatin-induced kaolin consumption. Thus, both farnesol and nerolidol exerted antiemetic efficacy against cytotoxic CINV.

Isomers of the farnesol and nerolidol inhibited $5-\mathrm{HT}_{3} \mathrm{R}-$ mediated 5-HT responses on visceral afferent neurons. Emetogenic chemotherapy increases 5-HT concentrations in the plasma and intestine (Schwörer et al., 1991; Castejon et al., 1999), and this elevated the activity of the gastrointestinal visceral afferents through $5-\mathrm{HT}_{3} \mathrm{R}$ activation (Horn et al., 2004). Hence, selective $5-\mathrm{HT}_{3} \mathrm{R}$ competitive antagonists are prescribed to alleviate CINV. Despite the appropriate use of diverse kinds of antiemetic drugs, many cancer patients still suffer from CINV (Pillai et al., 2011; Hernandez Torres et al., 2015) suggesting the need for new, alternative classes of antiemetic agents. Recent clinical trials found that add-on use of ginger augmented conventional
A

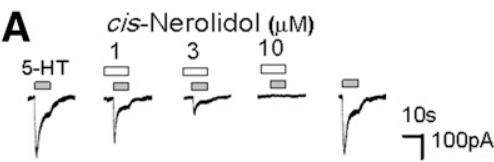

trans-Nerolidol $(\mu \mathrm{M})$
3

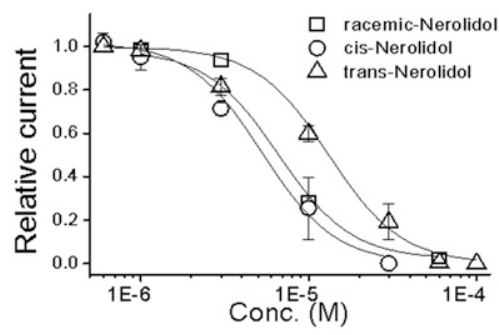

B
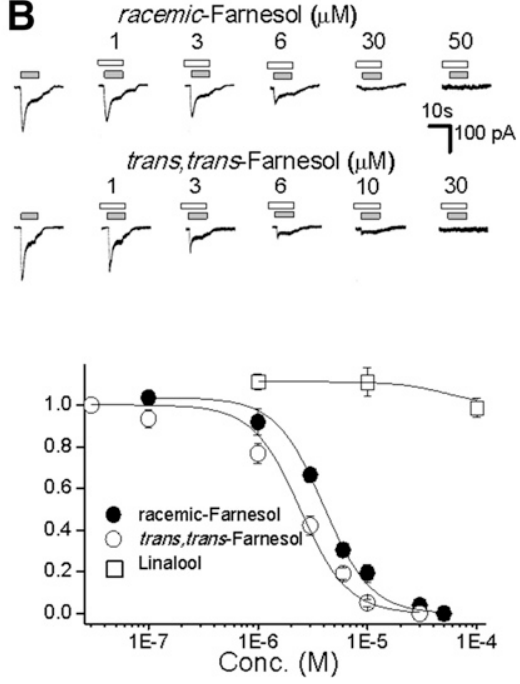

Fig. 6. Effects of isomers and racemic mixtures of the nerolidol and farnesol on 5-HT-induced responses. The neurons were pretreated for 1 minute with an external solution containing each compound before the simultaneous application with 5-HT. (A) The traces shown are inhibition of $3 \mu \mathrm{M}$ 5-HT-evoked current by cis- and trans-nerolidol. Upper and lower traces were taken from different sets of neurons. The graph represents the concentration-inhibition relationship of cis-, trans-, and racemic mixture-nerolidol. (B) The traces shown are inhibition of 5-HT-evoked current by racemic mixtureand trans, trans-farnesol. Upper and lower traces were taken from different set of neurons. The graph represents the concentration-inhibition relationship of racemic mixture- and trans, trans-farnesol and linalool. All responses were normalized to the peak current induced by $3 \mu \mathrm{M} 5$-HT alone. Each point and the vertical lines represent the mean and S.E.M. from five to seven neurons. 
A
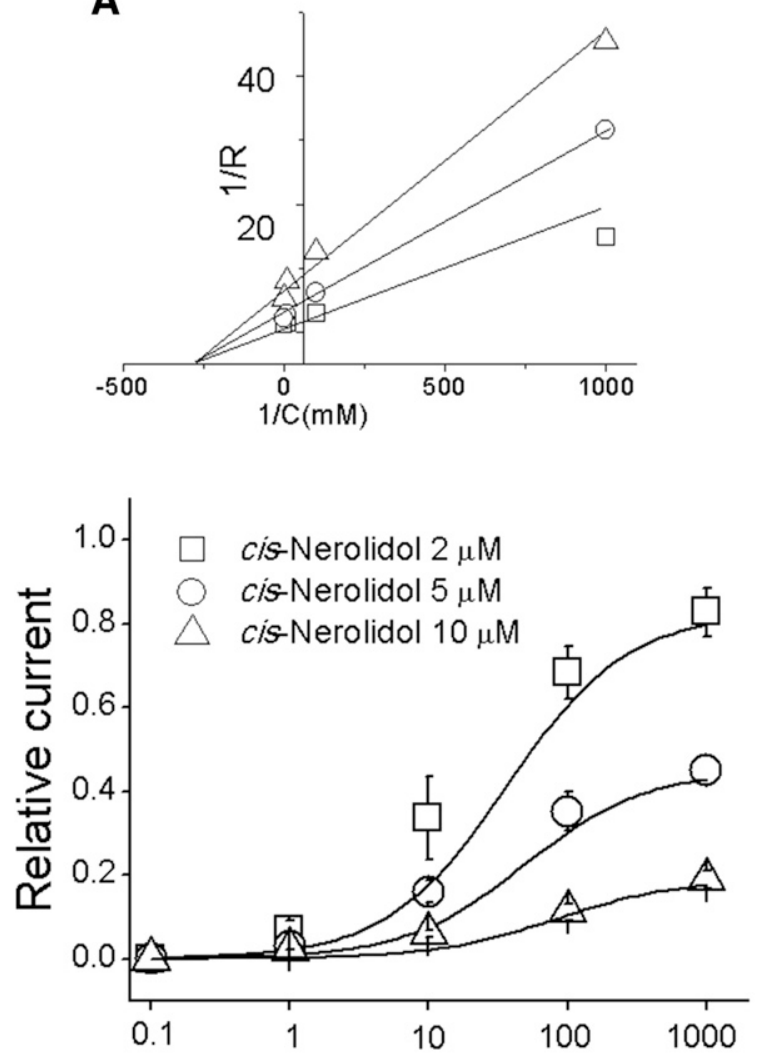

B
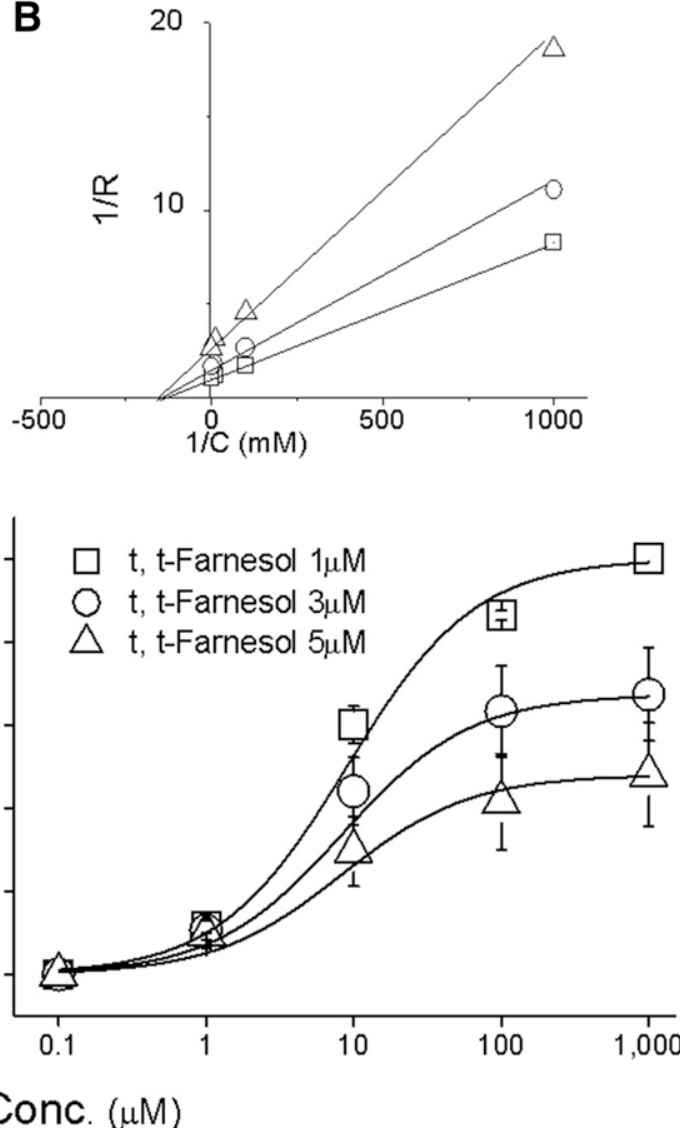

Fig. 7. Characterization of the inhibition by cis-nerolidol and trans, trans-farnesol (t,t-farnesol). (A) Lineweaver-Burk plot showing the mode of inhibition of cis-nerolidol. The concentration-response curves for 5-HT-induced responses were obtained in the presence of $2(\square), 5(O)$, and $10 \mu \mathrm{M}(\triangle)$ of $c i s$-nerolidol. (B) Lineweaver-Burk plot showing the mode of inhibition of t,t-farnesol. The concentration-response curves for 5-HT-induced responses were obtained in the presence of $1(\square), 3(O)$, and $5 \mu \mathrm{M}(\triangle)$ of t,t-farnesol. All responses were normalized for the peak current induced by $1 \mathrm{mM} 5$-HT alone. The IC $\mathrm{H}_{50}$ value was calculated by fitting the data using nonlinear regression (Origin 7). Each point is the average of five experiments. Vertical bars show + S.E.M.

antiemetic medications for resistant NV (Ryan et al., 2009; Pillai et al., 2011). These ginger-mediated antiemetic actions have been attributed to the noncompetitive inhibition of $5-\mathrm{HT}_{3} \mathrm{Rs}$ by its major constituents, gingerol and shogaol (Jin et al., 2014). Until now, several $5-\mathrm{HT}_{3} \mathrm{R}$ noncompetitive antagonists have been derived from plant constituents (i.e., citral, linalool, eucalyptol, and menthol) (Ashoor et al., 2013; Jarvis et al., 2016); however, none of these has greater inhibitory efficacy at $5-\mathrm{HT}_{3} \mathrm{Rs}$ than ginger constituents. Besides their antiemetic efficacy against CINV, their characterizations are quite incomplete. In contrast, isomers of the farnesol and nerolidol have lower $\mathrm{IC}_{50}$ values than any currently known compounds. Taken together, our current results indicate that

\section{TABLE 1}

Half-maximum inhibition concentration $\left(\mathrm{IC}_{50}\right)$ for nerolidol and farnesol isomers on serotonin (5-HT)-evoked currents in nodose neurons

The $\mathrm{IC}_{50}$ was determined by fitting the data obtained from five to six cells to concentration-inhibition equation in the method using a least-square fitting routine.

\begin{tabular}{lc}
\hline \multicolumn{1}{c}{ Compound } & $\mathrm{IC}_{50}(\mathrm{M})$ \\
\hline Cis-nerolidol & $4.89 \times 10^{-6}$ \\
Trans-nerolidol & $1.32 \times 10^{-5}$ \\
Racemic mixture-nerolidol & $6.58 \times 10^{-6}$ \\
Trans, trans-farnesol & $2.66 \times 10^{-6}$ \\
Tacemic mixture-farnesol & $3.96 \times 10^{-6}$ \\
\hline
\end{tabular}

isomers of the farnesol and nerolidol have promising potency in therapy-resistant CINV.

Farnesol Effects on Cisplatin-Induced Reduced Food Intake and Weight Loss. In addition to NV, cytotoxic chemotherapy causes appetite loss (anorexia) and weight loss (Kokal, 1985; Holmes, 1993; Andreyev et al., 1998; De Jonghe et al., 2009). Patient weight loss is associated with poor outcomes (Andreyev et al., 1998; Hess et al., 2007). The progesterone derivative megestrol acetate (MA) and cannabis-based medicines stimulate appetite and reduce weight loss in cancer patients (Jatoi et al., 2002; Walsh et al., 2005; Brisbois et al., 2011; Cuvelier et al., 2014). Despite their positive efficacy, significant side effects can curtail their use. For example, MA treatment can cause adrenal insufficiency in cancer patients with weight loss (Meacham et al., 2003; Orme et al., 2003). Meanwhile, the cannabisbased medicine induces psychotropic side effects through activating cannabinoid type 1 receptor in the central nervous system (Parmar et al., 2016). In contrast, farnesol is a common plant constituent long used in food, medicine, and perfume (Suryawanshi, 2011; Scheman et al., 2014). In many countries, farnesol flavors food so that there are no specific health concerns related to its ingestion (Lewis, 1989). Farnesol has antimicrobial and antineoplastic use (JabraRizk et al., 2006; Joo et al., 2010). Our report now shows promising use in chemotherapy-associated appetite and 
weight loss. Farnesol alone did not affect food intake in our saline-treated control animals (Fig. 3). Hence, its appetitestimulating efficacy is specific for anorexia of chemotherapy. The mechanism of action of farnesol represents a quite different approach compared with MA or cannabis-based therapies. Further studies are needed to elucidate these mechanisms.

In conclusion, we have found a novel antiemetic efficacy of the farnesol and nerolidol. These edible sesquiterpene alcohol constituents noncompetitively inhibited 5-HT-induced responses. This antiemetic mechanism of action may help inhibit conventional antiemetics (5- $\mathrm{HT}_{3} \mathrm{R}$ competitive antagonists) by overlapping the inhibition of serotonergic emetogenic signaling. Therefore, farnesol has promising efficacy for suppress antiemetic drug-resistant CINV and improving appetite and weight loss without serious side effects.

\section{Acknowledgments}

We thank Dr. M. C. Andresen for the critical reading of this article.

\section{Authorship Contributions}

Participated in research design: Lee, Jin.

Conducted experiments: Lee, Yang, Kim.

Performed data analysis: Lee, Kim, Jin.

Wrote or contributed to the writing of the manuscript: C. -S. Park, Y. S. Park, Jin.

\section{References}

Akaike N and Harata N (1994) Nystatin perforated patch recording and its applications to analyses of intracellular mechanisms. Jpn J Physiol 44:433-473.

Andreyev HJ, Norman AR, Oates J, and Cunningham D (1998) Why do patients with weight loss have a worse outcome when undergoing chemotherapy for gastrointestinal malignancies? Eur J Cancer 34:503-509.

Ashoor A, Nordman JC, Veltri D, Yang KH, Shuba Y, Al Kury L, Sadek B, Howarth FC, Shehu A, Kabbani N, et al. (2013) Menthol inhibits 5-HT3 receptor-mediated currents. J Pharmacol Exp Ther 347:398-409.

Babic T and Browning KN (2014) The role of vagal neurocircuits in the regulation of nausea and vomiting. Eur J Pharmacol 722:38-47.

Brisbois TD, de Kock IH, Watanabe SM, Mirhosseini M, Lamoureux DC, Chasen M, MacDonald N, Baracos VE, and Wismer WV (2011) Delta-9-tetrahydrocannabinol may palliate altered chemosensory perception in cancer patients: results of a randomized, double-blind, placebo-controlled pilot trial. Ann Oncol 22:2086-2093.

Castejon AM, Paez X, Hernandez L, and Cubeddu LX (1999) Use of intravenous microdialysis to monitor changes in serotonin release and metabolism induced by cisplatin in cancer patients: comparative effects of granisetron and ondansetron. $J$ Pharmacol Exp Ther 291:960-966.

Chan WK, Tan LT, Chan KG, Lee LH, and Goh BH (2016) Nerolidol: a sesquiterpene alcohol with multi-faceted pharmacological and biological activities. Molecules 21(5):529. https://doi.org/10.3390/molecules21050529.

Cuvelier GD, Baker TJ, Peddie EF, Casey LM, Lambert PJ, Distefano DS, Wardle MG, Mychajlunow BA, Romanick MA, Dix DB, et al. (2014) A randomized, double-blind, placebo-controlled clinical trial of megestrol acetate as an appetite stimulant in children with weight loss due to cancer and/or cancer therapy. Pediatr Blood Cancer 61:672-679.

De Jonghe BC, Lawler MP, Horn CC, and Tordoff MG (2009) Pica as an adaptive response: kaolin consumption helps rats recover from chemotherapy-induced illness. Physiol Behav 97:87-90.

Devlin EJ, Denson LA, and Whitford HS (2017) Cancer treatment side effects: a meta-analysis of the relationship between response expectancies and experience. $J$ Pain Symptom Manage 54:245-258.e2.

Haiderali A, Menditto L, Good M, Teitelbaum A, and Wegner J (2011) Impact on daily functioning and indirect/direct costs associated with chemotherapy-induced nausea and vomiting (CINV) in a U.S. population. Support Care Cancer 19:843-851.

Hernandez Torres C, Mazzarello S, Ng T, Dranitsaris G, Hutton B, Smith S, Munro A, Jacobs C, and Clemons M (2015) Defining optimal control of chemotherapyinduced nausea and vomiting-based on patients' experience. Support Care Cancer 23:3341-3359.

Hess LM, Barakat R, Tian C, Ozols RF, and Alberts DS (2007) Weight change during chemotherapy as a potential prognostic factor for stage III epithelial ovarian carcinoma: a Gynecologic Oncology Group study. Gynecol Oncol 107: $260-265$.
Hofman M, Morrow GR, Roscoe JA, Hickok JT, Mustian KM, Moore DF, Wade JL, and Fitch TR (2004) Cancer patients' expectations of experiencing treatment-related side effects: a University of Rochester Cancer Center-Community Clinical Oncology Program study of 938 patients from community practices. Cancer 101:851-857.

Holmes S (1993) Food avoidance in patients undergoing cancer chemotherapy. Support Care Cancer 1:326-330.

Horn CC, Richardson EJ, Andrews PL, and Friedman MI (2004) Differential effects on gastrointestinal and hepatic vagal afferent fibers in the rat by the anti-cancer agent cisplatin. Auton Neurosci 115:74-81.

Jabra-Rizk MA, Meiller TF, James CE, and Shirtliff ME (2006) Effect of farnesol on Staphylococcus aureus biofilm formation and antimicrobial susceptibility. Antimicrob Agents Chemother 50:1463-1469.

Jarvis GE, Barbosa R, and Thompson AJ (2016) Noncompetitive inhibition of 5-HT3 receptors by citral, linalool, and eucalyptol revealed by nonlinear mixed-effects modeling. J Pharmacol Exp Ther 356:549-562.

Jatoi A, Windschitl HE, Loprinzi CL, Sloan JA, Dakhil SR, Mailliard JA, Pundaleeka S, Kardinal CG, Fitch TR, Krook JE, et al. (2002) Dronabinol versus megestrol acetate versus combination therapy for cancer-associated anorexia: a North Central Cancer Treatment Group study. J Clin Oncol 20: $567-573$.

Jin Z, Lee G, Kim S, Park CS, Park YS, and Jin YH (2014) Ginger and its pungent constituents non-competitively inhibit serotonin currents on visceral afferent neurons. Korean J Physiol Pharmacol 18:149-153.

Joo JH and Jetten AM (2010) Molecular mechanisms involved in farnesol-induced apoptosis. Cancer Lett 287:123-135.

Kim S, Jin Z, Lee G, Park YS, Park CS, and Jin YH (2015) Prostaglandin potentiates 5 -HT responses in stomach and ileum innervating visceral afferent sensory neurons. Biochem Biophys Res Commun 456:167-172.

Kokal WA (1985) The impact of antitumor therapy on nutrition. Cancer $\mathbf{5 5}(1 \mathrm{Suppl})$ : 273-278.

Lewis JR (1989) Food Additives Handbook, Chapman \& Hall, New York.

Meacham LR, Mazewski C, and Krawiecki N (2003) Mechanism of transient adrenal insufficiency with megestrol acetate treatment of cachexia in children with cancer. $J$ Pediatr Hematol Oncol 25:414-417.

Murase K, Ryu PD, and Randic M (1989) Excitatory and inhibitory amino acids and peptide-induced responses in acutely isolated rat spinal dorsal horn neurons. Neurosci Lett 103:56-63.

Nampoothiri SV, Venugopalan VV, Joy B, Sreekumar MM, and Menon AN (2012) Comparison of essential oil composition of three ginger cultivars from sub Himalayan region. Asian Pac J Trop Biomed 2:S1347-S1350.

Orme LM, Bond JD, Humphrey MS, Zacharin MR, Downie PA, Jamsen KM, Mitchell SL, Robinson JM, Grapsas NA, and Ashley DM (2003) Megestrol acetate in pediatric oncology patients may lead to severe, symptomatic adrenal suppression. Cancer 98:397-405.

Parmar JR, Forrest BD, and Freeman RA (2016) Medical marijuana patient counseling points for health care professionals based on trends in the medical uses, efficacy, and adverse effects of cannabis-based pharmaceutical drugs. Res Social Adm Pharm 12:638-654.

Pillai AK, Sharma KK, Gupta YK, and Bakhshi S (2011) Anti-emetic effect of ginger powder versus placebo as an add-on therapy in children and young adults receiving high emetogenic chemotherapy. Pediatr Blood Cancer 56: $234-238$.

Ryan JL, Heckler C, Dakhil SR, Kirshner J, Flynn PJ, Hickok JT, and Morrow GR (2009) Ginger for chemotherapy-related nausea in cancer patients: a URCC CCOP randomized, double-blind, placebo-controlled clinical trial of 644 cancer patients (Abstract). J Clin Oncol 27(15 Suppl). 9511-9511.

Ryan J, Heckler CE, Roscoe JA, Dakhil SR, Kirshner J, Flynn PJ, Hickok JT, and Morrow GR (2012) Ginger (Zingiber officinale) reduces acute chemotherapy-induced nausea: a URCC CCOP study of 576 patients. Support Care Cancer 20:1479-1489.

Scheman A, Scheman N, and Rakowski EM (2014) European directive fragrances in natural products. Dermatitis 25:51-55.

Schwörer H, Racké K, and Kilbinger H (1991) Cisplatin increases the release of 5 -hydroxytryptamine (5-HT) from the isolated vascularly perfused small intestine of the Guinea-pig: involvement of 5-HT3 receptors. Naunyn Schmiedebergs Arch Pharmacol 344:143-149.

Suryawanshi S (2011) An overview of Citrus aurantium used in treatment of various diseases. Afr J Plant Sci 5:390-395.

Suzuki H, Asakawa A, Amitani H, Nakamura N, and Inui A (2013) Cancer cachexia-pathophysiology and management. J Gastroenterol 48:574-594.

Takeda N, Hasegawa S, Morita M, and Matsunaga T (1993) Pica in rats is analogous to emesis: an animal model in emesis research. Pharmacol Biochem Behav 45:817-821.

Tyers MB and Freeman AJ (1992) Mechanism of the anti-emetic activity of 5-HT3 receptor antagonists. Oncology 49:263-268.

Walsh D, Kirkova J, and Davis MP (2005) The efficacy and tolerability of long-term use of dronabinol in cancer-related anorexia: a case series. J Pain Symptom Manage 30:493-495.

Address correspondence to: Dr. Young-Ho Jin, Department of Physiology, College of Medicine, Kyung Hee University, 26 Kyungheedae-ro, Dongdaemungu, Seoul 20117, Republic of Korea. E-mail: jinyh@khu.ac.kr 